\title{
6. ENGINEERING REPORT ON THE NAVIDRILL CORE BARREL (NCB-124E) ${ }^{1}$
}

\author{
David P. Huey²
}

\section{INTRODUCTION}

The navidrill core barrel (NCB) is a motor-driven core barrel designed to apply mining-type, diamond-coring technology to ODP operations in a format compatible with advanced hydraulic piston corer (APC) and extended core barrel (XCB) coring, i.e., in the same bottom-hole assembly (BHA). The NCB is wireline deployable. The diamond bit and core barrel are driven by a slimline, positive-displacement mud motor that is part of the core-barrel assembly. Development of the NCB has been under way at ODP since 1984. Several land tests and sea trials have yielded a second-generation tool that still has had relatively little impact on ODP operations. Various versions have been field tested during very limited opportunities on Legs 104, 114, 118, and 121

The NCB was ready for more sea trials after its first successful deployment during Leg 121. It was desired to give the tool as much downhole time as possible both for "wringing out" the basic design and concept as well as for testing its effectiveness as a coring device specifically in chert and soft-sediment interbeds. Among the improvements made to the system since Leg 121 were new titanium flex shafts in the mud motors, improved torque-reaction segments, and two all-new mud-motor designs devised by Eastman-Christensen. Both of the new motors were designed to be capable of producing more torque and slightly higher speeds than the best motors previously available in their size range. The motors were fabricated in virtually the same length as previous motors used with the NCB; thus no adjustment to the BHA was required. Special motor-adaptor crossover subs were made on board the ship to allow the motors to be assembled into the NCB standard assembly. The new motor adaptors ordered from Eastman-Christensen with the new motors did not arrive.

\section{CORING DEPLOYMENTS-SITE 777}

After establishing the depth of the hard strata $(38.0 \mathrm{mbsf}$ in Holes 777A through 777D and 41.5 mbsf in Holes 777E and $777 \mathrm{~F}$ ), the NCB was deployed and attempts to core were made nine times. Of these deployments, two should be disregarded as legitimate coring attempts because of mechanical failures unrelated to lithology. One tool failed to unlatch and begin coring when a previously unused thruster unit was assembled to the motor and core-barrel sections. The landing sleeve on the thruster unit had been inadvertently jammed during initial assembly in Manila and would not move, thus preventing the tool from initiating the coring sequence. One other deployment was thwarted by a malfunctioning motor. Although the fact was not discovered until later, the motor was apparently bad when delivered from the factory (specifically ordered for this leg) and would not rotate under any flow or pressure conditions and thus never was able to rotate the core barrel to cut any core.

\footnotetext{
${ }^{1}$ Harding, B. W., Storms, M. A., et al., 1990. Proc. ODP, Init. Repts., 124E: College Station, TX (Ocean Drilling Program).

2 Shipboard engineering and scientific parties are as given in the listing of participants preceding the contents.
}

The first two NCB deployments suffered catastrophic failures of the 3 3/4-in. diamond core bits. In both cases the bits fractured about $11 / 2$ in. from the crown in what appeared to be low-cycle fatigue of the metal bodies. Such a failure mode was totally unexpected and is difficult to explain, since the bits are standard products of the mining industry and are routinely subjected to generally equivalent conditions in normal diamondcoring operations. Back-to-back failures of this sort at Site 777 suggested that the specific conditions imposed on the bits in Holes $777 \mathrm{~B}$ and $777 \mathrm{C}$ were in some way extreme. The most likely explanation was excess bending at the bit face caused by lack of horizontal stabilization of the BHA in the extremely soft sediment.

To combat the stabilization problem, the remaining NCB attempts in Holes 777D and 777E were conducted only after making $10 \mathrm{~m}$ or more of hole into the chert/porcellanite layer below the sediment overlayer (using XCB) in order to make a firm supporting medium for the lowermost drill collar. This approach apparently met with success, as no further indications on the NCB bits of fatigue failure were observed. Another artifact of the early NCB deployments were belled box connections on either the NCB bits or the lower core barrel, or both. The indications were common evidence of overtorque, although the probable amount of torque required to cause such damage would be several times the maximum stall torque possible from the mud motors. The cause of this troublesome phenomenon was not determined, and it had no direct effect on the results of the coring attempts.

Three valid coring deployments were made in Hole 777D. In each case the NCB appeared to have functioned properly in all mechanical aspects, but only minimal amounts of core were recovered. Indicated penetrations and core recoveries for the three runs are as follows:

\begin{tabular}{rcc}
\multicolumn{1}{c}{ Core } & $\begin{array}{c}\text { Penetration } \\
(\mathrm{m})\end{array}$ & $\begin{array}{c}\text { Recovery } \\
(\mathrm{m})\end{array}$ \\
\hline $124 \mathrm{E}-777 \mathrm{D}-2 \mathrm{~N}$ & 1.1 & 0.27 \\
$3 \mathrm{~N}$ & 4.1 & 0.37 \\
$4 \mathrm{~N}$ & 4.0 & 0.50
\end{tabular}

The indicated penetration was derived by measuring the amount of paint removed on the core barrel that had extended beyond the bit face. There was considerable doubt as to the legitimacy of this measurement, since the core recovery was slight by comparison and the core catchers were jammed tight all three times. In order for the amount of penetration indicated in Cores 124E-777D-3N and $-4 \mathrm{~N}$ to have occurred without a corresponding recovery of core, the core barrel would have had to advance into the sediment with the core firmly blocked (supposedly impossible with a mining-type diamond coring system in hard formation), or the core block would have had to occur coincidentally in both cases at the very end of the cored interval, with the missing core representing soft material that had been washed away. Neither explanation was particularly satisfying, but further attempts to clarify the issue on subsequent tries were inconclusive when other problems intervened. Hole 777D was terminated when an external spring on the NCB thruster unit shat- 
tered (assumed to have been caused by stress corrosion) and caused the NCB to become irretrievably jammed in the BHA, forcing a full pipe round trip to dislodge it.

Following the two aborted deployments in Hole 777E in which the faulty Mach $1 \mathrm{C}$ mud motor was used, two additional legitimate NCB core runs were conducted. In both cases, penetration of the coring assembly into the formation was virtually nil, and the total recovery was only a few chunks of fractured chert. All indications were that the mud motor had stalled in both cases owing to excessive torque demands at the bit/chert interface. It was concluded that the jamming was an inevitable result of attempting to start a hole in fractured chert rubble that was present at the bottom of the hole whenever the NCB was deployed. Further NCB deployments were not considered worthwhile, since there was no effective way to clean the bottom of the hole thoroughly between NCB runs.

\section{NCB DECK TESTS}

Time was set aside to deck-test the NCB on Leg 124E rather than to conduct additional downhole runs in order to clarify two important points: were the two mud motors functioning normally, and was the thruster unit unlatching and allowing the NCB to core ahead as designed?

Both mud motors were set up on a makeshift test stand on the rig floor, and drill water was pumped at high pressure into them. The Mach 1P motor used on seven of the nine NCB runs functioned absolutely normally, with rotation initiating at about $100 \mathrm{psi}$. The Mach $1 \mathrm{C}$ motor failed to rotate under any combination of flow and pressure up to $300 \mathrm{gpm}$ and $1500 \mathrm{psi}$, far exceeding the maximum required parameters for the motor as quoted by the manufacturer. Mysteriously, the rotor was not frozen and could be made to rotate within the stator, with moderate torque applied externally with pipe wrenches. The motor was packed for immediate return to the manufacturer for failure analysis.

To demonstrate that the thruster unit was operating correctly, the NCB with the Mach 3 mud motor (low torque, high speed) was set on top of a barrel of cement on the rig floor, and a drill test was conducted. The thruster unit allowed the NCB to unlatch and initiate the coring sequence properly. The motor was unable to penetrate into the cement, however. The NCB stalled in the semi-cured cement and actually began to transmit lefthand stall torque to the suspended $\mathrm{BHA}$, causing it to rotate backward despite up to $20,000 \mathrm{lb}$ weight on the XCB bit against the cement. This result was unexpected but served to demonstrate how easily the NCB can stall at initial contact with a soft formation, especially when using the lower torque motor.

\section{SUMMARY AND CONCLUSIONS}

Despite typical prototype-system problems with jammed sleeves and faulty mud motors and "Murphy's Law" (a shattered thruster spring and broken coring line), the NCB performed reasonably well. Two problems dominated the use of the NCB and accounted for the poor overall core recovery. The inability to stabilize the BHA in the shallow holes probably led to the fatigue failures of two diamond core bits and may well have contributed to the mysterious over-torqued connections. When the bit bodies fatigued and separated during a core run, the advance of the NCB in the formation was certainly terminated, and it cannot be said whether a good core would have been achieved. Core blocking in the core catchers and motor stalling, either or both of which dominated most of the "promising" NCB core runs, were results of the interbedded chert and soft sediments in the hole. Although all normal attempts were made to condition the holes between NCB core runs, it is almost certain that the bottom of the hole contained unremoved chips from the previous cored or drilled-down interval. This rubble surface was the first thing encountered by the NCB bit when it unlatched and began the coring sequence. In typical mining diamond coring operations, the driller would start such a core run with very light weight on the bit and controlled revolutions per minute (rpm) until the bit was seated smoothly in fresh rock. The NCB is not capable of such delicacy and plunges ahead into a core jam or stall condition all too often.

The NCB showed more promise than the XCB in interbedded-chert coring but did not prove to be worthy of scientific commitment to a known interbedded-chert locale unless certain improvements can be successfully made to the overall NCB system. The mud motors and bits that were used appeared to be capable of cutting core in the chert layers, as evidenced by welltrimmed pieces of chert/banded porcellanite in Cores 124E$777 \mathrm{~B}-5 \mathrm{~N}$ and $124 \mathrm{E}-777 \mathrm{C}-2 \mathrm{~N}$. These two cores were cut in the upper extremities of the chert sequence and may have represented more readily coreable zones with less hard cuttings as fill between cores. When progress was made into what appeared to be more lithified zones deeper in the chert sequence, the NCB either stalled on the rubble or jammed the chunks in the core catcher, or both. The inherent characteristic of the NCB in its current configuration (as recognized long before Leg 124E) is its tendency to increase its downward force against the formation (weight on bit) as stall of the motor commences. This tendency causes almost certain stalling unless the bit can seat itself and get a smooth cutting action started. Even if equilibrium is achieved and coring of the chert layers proceeds smoothly, it can be interrupted and stalled by breaking through into a soft sediment layer and plowing ahead faster than the bit can trim the soft core. This, then, results in a core block and/or motor stall that cannot be corrected by any action taken on deck by the driller. The net result of these problems and tendencies is generally inefficient or ineffective coring in chert/sediment interbeds using the NCB. Significant design changes to the NCB system will be required to eliminate these problems.

One NCB-related device slated for testing at Site 777 was never used. The "dipstick" tool was intended for use after one or two successful NCB core runs during which there had been strong evidence of significant core-bit penetration. Since most of the NCB runs had questionable penetration results, no opportune time to deploy the dipstick occurred.

The dipstick tool was a specialty device intended to be run after any NCB core run to measure the depth of the $33 / 4$-in. pilot hole created by the NCB. Under normal circumstances it is not possible to determine positively how much penetration ahead of the main bit is achieved by the NCB on any given core run. Nor is it possible to guarantee that the small pilot hole does not fill up with cuttings between tool deployments. The development of the new "geoprops probe" required the answer to both of these questions following as many NCB core runs as possible, since the success of the geoprops probe is dependent on the availability of a relatively clean NCB-cut $33 / 4$-in. pilot hole. If the NCB holes were found to fill repeatedly with cuttings and debris, the concept of the geoprops probe would have to be altered to include some means of reopening the pilot hole before insertion of the probe.

\section{FUTURE PLANS}

There is nothing fundamentally wrong with the mechanics of the NCB as it is now designed. The problem is that the mechanics do not adequately satisfy the needs of the coring assignment that must be successfully achieved each time the NCB is deployed. In order to utilize thin-kerf, diamond coring technology in a wireline-deployable coring tool, the device must be able to operate within the parametric envelope that limits that technology. Diamond coring, it turns out, is highly operator-sensitive. A remote tool, with no means of operator feedback or interven- 
tion, must be able to sense conditions constantly and adjust appropriately. The NCB as it is now designed cannot make those adjustments well enough or fast enough to prevent coring failure-i.e., stalling or core blocking.

The testing achieved to date has demonstrated that, under ideal circumstances, the NCB has the capability to produce high-quality cores from formations in which no other ODP tool can be expected to produce such cores. Additionally, the NCB is the only viable means of extending an APC/XCB hole into fully lithified basement, thus eliminating the need for a drill-string round trip for a different coring system such as the rotary core barrel (RCB). For these reasons it is worthwhile to continue NCB development. The next step must be a third-generation tool, which will be designed to eliminate the three primary shortcomings of the existing design:

1. The tool stalls too easily and drives itself into a worse stall when the symptoms begin, rather than backing off to reduce the stall.

2. When the motor and core barrel unlatch at the start of the coring sequence, the barrel lunges into the bottom of the hole. Instead, it must be designed to approach the bottom of the hole gradually with full rotation speed and light bit weight until the bit has had a chance to seat itself and "condition" the hole bottom for continued coring.

3. The propensity toward core blocking is much too great; the anti-jam device used so far is poorly designed and not able to live up to its billing. It is built around a sound concept, however, and can be improved.

\section{Ms 124E-106}

\section{APPENDIX \\ Data Summary for Leg 124E Navidrill Core Runs Core $777 \mathrm{~B}-5 \mathrm{~N}$}

General

Date:

Water depth $(\mathrm{m})$

Depth (mbsf):

APC/XCB bit:

BHA notes:

9 February 1989
5810.5
38.4
RBI $101 / 2$-in., 5-cone C-3, 5
$\quad \times 14$ nozzles
6 DC, w/non-mag latch sub

NCB details

Motor:

Bit type:

Core-catcher type:

Thruster nozzles:

Flow-divider nozzles:

Inner tube/liner:

Anti-jam/HWD4 standard bearing:

Deployment mode:

Unlatch mech. reset when recvd.?

\section{Operating data}

Pumping (coring?) time:

Pump rate:

Calculated weight on NCB bit:

Top-drive rpm:

Compensated weight on $\mathrm{XCB}$ bit:

Hole conditions:

Assumed formation:

Used surface set

Collet

14-14

11-11-18

Plastic liner

\section{Standard bearing} $42 \mathrm{~min}$

Yes

\section{$30 \min$}

$\overline{15}$

$10-12 \mathrm{k}$ sediment

Chert/porcellanite interbedded
Results

Indicated penetration $(\mathrm{m})$ :

Amount of core (m):

Core description:

Bit condition:

Other mechanical problems:

\section{Core $777 \mathrm{C}-2 \mathrm{~N}$}

General

Date:

Water depth $(\mathrm{m})$ :

Depth (mbsf):

$\mathrm{APC} / \mathrm{XCB}$ bit:

BHA notes:

NCB details

Motor:

Bit type:

Core-catcher type:

Thruster nozzles:

Flow-divider nozzles:

Inner tube/liner:

Anti-jam/HWD4 standard bearing:

Deployment mode:

Unlatch mech, reset when rcvd.?:

Operating data

Pumping (coring?) time:

Pump rate:

Calculated weight on NCB bit:

Top-drive rpm:

Compensated weight on XCB bit:

Hole conditions:

Assumed formation:

Results

Indicated penetration $(\mathrm{m})$ :

Amount of core $(\mathrm{m})$ :

Core description:

Bit condition:

Freefall, pumped w/40 strokes,

160-190 gpm, 5-in. pump liners

BHA poorly buried in very soft with?
1.47

0.72

Banded porcellanite, dark brown, very hard, mostly broken, but some 3-in. pieces well trimmed, apparent hole drift of $20^{\circ}-30^{\circ}$

Body completely separated $11 /$ 2 in. from crown

Torque segments okay
9 February 1989

5810.5

43.4

RBI 10 1/2 in., 5-cone C-3, 5 $\times 14$ nozzles

$6 \mathrm{DC}$ w/non-mag latch sub

Mach 1P, drain-hole type

New green impregnated

Collet

16-16

11-11-18

Plastic liner

Standard bearing

Freefall, $43 \mathrm{~min}$ to bottom

Yes

$70 \mathrm{~min}$

140-185 gpm, 5-in. pump liners

15

$10-12 \mathrm{k}$

4.6-m rathole into hard streak under soft

Chert/porcellanite interbedded with?

3.96 (false indication?)

0.71

Jammed and baked, chert chunks and clay

Broken, $11 / 2$ in. of crown lost, same as Core $5 \mathrm{~N}$, Hole 777B

Other mechanical problems: $\quad$ Bit box belled noticeably, liner partially melted, torque segments okay

Core $777 \mathrm{D}-2 \mathrm{~N}$

General

Date:

Water depth $(\mathrm{m})$ :

Depth (mbsf):

APC/XCB bit:

5810.5

50.6

BHA notes:

RBI $101 / 2$ in., 5-cone C-3, 5 $\times 14$ nozzles

6 DC w/non-mag latch sub

NCB details

Motor:

Bit type:

Core-catcher type:

Mach 1P, drain-hole type

New surface set, Eastman-

Christensen

Collet 
Thruster nozzles:

Flow-divider nozzles:

Inner tube/liner:

Anti-jam/HWD4 standard bearing:

Deployment mode:

Unlatch mech. reset when rcvd.?:

Operating data

Pumping (coring?) time:

Pump rate:

Calculated weight on NCB bit:

Top-drive rpm:

Compensated weight on $\mathrm{XCB}$ bit:

Hole conditions:

Assumed formation:

Results

Indicated penetration $(\mathrm{m})$ :

Amount of core (m):

Core description:

Bit condition:

Other mechanical problems:

\section{Core 777D-3N}

Date:

Water depth $(\mathrm{m})$ :

Depth (mbsf):

APC/XCB bit:

BHA notes:

NCB details

Motor:

Bit type:

Core-catcher type:

Thruster nozzles:

Flow-divide nozzles:

Inner tube/liner:

Anti-jam/HWD4 standard bearing:

Deployment mode:

Unlatch mech. reset when rcvd.?:

\section{February 1989}

5810.5

51.7

RBI $101 / 2$ in., cone C-3, $5 \times$ 14 nozzles

-

Mach 1P, drain-hole type

Used, piloted impregnated

Collet

20-20

11-11-18

Plastic liner

Standard bearing

Freefall, $60 \mathrm{spm}, 33 \mathrm{~min}$ to bottom

Yes

Operating data

Pumping (coring?) time:

Pump rate:

Calculated weight on NCB bit:

Top-drive rpm:

Compensated weight on XCB bit:

Hole conditions:

Assumed formation:

Results

Indicated penetration $(\mathrm{m})$ :

Amount of core (m):

Core description:

Bit condition:

Other mechanical problems:

\section{Core 777D-4N}

General

Date:

Water depth $(\mathrm{m})$ :

10 February 1989

Depth (mbsf):

APC/XCB bit:

5810.5

55.8

RBI 10 1/2 in., 5-cone C-3, 5

$\times 14$ nozzles

BHA notes:

$6 \mathrm{DC}$ w/non-mag latch sub

NCB details

Motor:

Bit type:

Core-catcher type:

Thruster nozzles:

Flow-divider nozzles:

Inner tube/liner:

Anti-jam/HWD4 standard bearing:

Deployment mode:

Unlatch mech. reset when rcvd.?:

Mach 1P, drain-hole type Used, piloted impregnated

Collet

20-20

11-11-20

Plastic liner

Anti-jam

Freefall, $36 \mathrm{~min}$ to bottom

See notes at end

Operating data

Pumping (coring?) time:

Pump rate:

Calculated weight on NCB bit:

Top-drive rpm:

Compensated weight on XCB bit:

Hole conditions:

Assumed formation:

$41 \mathrm{~min}$

170-180 gpm

None

10-12k

Okay

Chert/porcellanite interbedded with?

Results

Indicated penetration $(\mathrm{m})$ :

Amount of core $(\mathrm{m})$ :

Core description:

4.2 (false indication?)

0.5

Jammed and baked, a few welltrimmed then fractured pieces of banded porcellanite

Bit condition:

Face discharge jets plugged, worn on crown but good diamond exposure and excellent $\mathrm{OD} / \mathrm{ID}$ gauge protection

Other mechanical problems:

HWD4 core-barrel lower box belled out, torque segments worn on one side but hinged smoothly; anti-jam bearing frozen

\section{NOTES-Hole 777D, Core $4 \mathrm{~N}$}

The core barrel was found stuck at the bit because the flat spring in the thruster unit had shattered and jammed pieces throughout the BHA. The tool could not pass through the double-window latch sleeve or the top sub. Heavy jarring with W/L link jars destroyed the RS overshot but could not free the core barrel, forcing a round trip of the pipe. On deck, the 3-lug $\mathrm{Q} / \mathrm{R}$ was found disengaged, but (remarkably) the lower core barrel stayed in the BHA.

After loss of the flat spring downhole, the preload nut for the spring pack had screwed down, allowing the split sleeves to fall out, which also helped jam the mechanism in the BHA.

The downhole jarring caused the thruster unit to overstroke in the "up" direction. Later, the unit would not reset, and excess play was observed in the balls and grooves.

\section{Core $777 \mathrm{E}-2 \mathrm{~N}$}

General

Date:

Water depth $(\mathrm{m})$ :

12 February 1989

5810.5 
Depth (mbsf):

APC/XCB bit:

BHA notes:

NCB details

Motor:

Bit type:

Core-catcher type:

Thruster nozzles:

Flow-divider nozzles:

Inner tube/liner:

Anti-jam/HWD4 standard bearing:

Deployment mode:

Unlatch mech. reset when rcvd.?:

Operating data

Pumping (coring?) time:

Pump rate:

Calculated weight on NCB bit:

Top-drive rpm:

Compensated weight on $\mathrm{XCB}$ bit:

Hole conditions:

Assumed formation:

Results

Indicated penetration:

Amount of core:

Core description:

Bit condition:

Other mechanical problems:
60.5

$\times 14$ nozzles

$6 \mathrm{DC}$ w/non-mag latch sub

Mach 1C, tight rotor

Used, piloted surface set

Dog type

20-20

11-11-18

Plastic liner

Standard bearing

Freefall, $30 \mathrm{~min}$ to bottom

Never unlatched

15 min (intentional early stop)

185-190 gpm

-

$\overline{10}-12 \mathrm{k}$

Okay

Chert/porcellanite interbedded with?

None

None

None

No wear, never contacted formation

Landing sleeve jammed owing to incorrect assembly. Sand line broke while recovering core barrel, allowing NCB to freefall $1000 \mathrm{~m}$ back to bit.

Mach $1 \mathrm{C}$ motor nonfunctional.

Core $777 \mathrm{E}-2 \mathrm{~N}-$ Second try

General

Date:

Water depth $(\mathrm{m})$ :

Depth (mbsf):

APC/XCB bit:

BHA notes:

NCB details

Motor:

Bit type:

Core-catcher type:

Thruster nozzles:

Flow-divider nozzles:

Inner tube/liner:

Anti-jam/HWD4 standard bearing:

Deployment mode:

Unlatch mech, reset when revd.?:

Operating data

Pumping (coring?) time:

Pump rate:

Calculated weight on NCB bit:

Top-drive rpm:

Compensated weight on XCB bit: $\quad \overline{10}-12 \mathrm{k}$

12 February 1989

5810.5

60.5

RBI 10 1/2 in., 5-cone C-3, 5 $\times 14$ nozzles

$6 \mathrm{DC}$ w/non-mag latch sub

Mach $1 C$, tight rotor

Used, piloted surface set

Dog type

20-20

11-11-18

Plastic liner

Standard bearing

Freefall, $30 \mathrm{~min}$ to bottom

May never have unlatched

$60 \mathrm{~min}$

100-160 gpm

-
RBI 10 1/2 in., 5-cone C-3, 5

Hole conditions:

Assumed formation:

Good

Chert/porcellanite interbedded with?

Results

Indicated penetration:

Amount of core:

Core description:

Bit condition:

Other mechanical problems:

Core 777E-2N-Third Try

General

None

None

None

No apparent contact with formation

Mach IC motor nonfunctional
Date:

Water depth (m):

Depth (mbsf):

$\mathrm{APC} / \mathrm{XCB}$ bit:

BHA notes:

NCB details

Motor:

Bit type:

Core-catcher type:

Thruster nozzles:

Flow-divider nozzles:

Inner tube/liner:

Anti-jam/HWD4 standard bearing:

Deployment mode:

Unlatch mech. reset when rcvd.?:

Operating data

Pumping (coring?) time:

Pump rate:

Calculated weight on NCB bit:

Top-drive rpm:

Compensated weight on $\mathrm{XCB}$ bit:

Hole conditions:

Assumed formation:

12 February 1989

5810.5

60.5

RBI 10 1/2 in., 5-cone C-3, 5 $\times 14$ nozzles

$6 \mathrm{DC}$ w/non-mag latch sub

Mach 1P, drain-hole type

Used, piloted surface set

Dog type

14-14

11-11-16

Plastic liner

Standard bearing

Freefall

Yes

$34.5 \mathrm{~min}$

$80-160 \mathrm{gpm}$

$-$

10-12k

Poor, 7-m fill getting back to bottom

Chert/porcellanite interbedded with ?

Results

Indicated penetration $(\mathrm{m})$ :

Amount of core (m):

0.5

0.21

A few chunks and a handful of small chips

Bit condition:

Other mechanical problems:

Pristine

None

Core 777E-3N

General

Date:

Water depth (m):

Depth (mbsf):

APC/XCB bit:

BHA notes:

12 February 1989

5810.5

61.5

RBI 10 1/2 in., 5-cone C-3, 5

$\times 14$ nozzles

$6 \mathrm{DC}$ w/non-mag latch sub

NCB details

Motor:

Bit type:

Core-catcher type:

Thruster nozzles:

Flow-divider nozzles:
Mach 1P, drain-hole type Used, piloted surface set

Dog type

20-14

11-11-16 


\section{P. HUEY}

Inner tube/liner:

Anti-jam HWD4 standard bear-

$$
\text { ing: }
$$

Deployment mode:

Unlatch mech, reset when rcvd.?:

Operating data

Pumping (coring?) time:

Pump rate:

Calculated weight on NCB bit:

Top-drive rpm:

Compensated weight on $\mathrm{XCB}$ bit:

Hole conditions:
Plastic liner

Standard bearing

Freefall

Yes

$16.5 \mathrm{~min}$

50-170 gpm (abnormally high pressures)

5

20k

Poor, $1 \mathrm{~m}$ fill getting back to bottom
Assumed formation:

Results

Indicated penetration $(\mathrm{m})$ :

Amount of core:

Core description:

Bit condition:

Other mechanical problems:
Chert/porcellanite interbedded with ?

1 (more likely matches amount $\mathrm{XCB}$ bit was off bottom when NCB unlatched)

None

None

Slightly worn, 3 jets plugged with chips

Apparent stall in rubble, paint on landing shoulder indicated proper landing. 